\title{
EFFECT OF LIGNIN CONTENT ON ENZYMATIC HYDROLYSIS OF FURFURAL RESIDUES
}

\author{
Ran Sun, Xianliang Song, Runcang Sun, and Jianxin Jiang * \\ The enzymatic saccharification of pretreated furfural residues with \\ different lignin content was studied to verify the effect of lignin \\ removal in the hydrolysis process. The results showed that the \\ glucose yield was improved by increasing the lignin removal. A \\ maximum glucose yield of $96.8 \%$ was obtained when the residue with \\ a lignin removal of $51.4 \%$ was hydrolyzed for $108 \mathrm{~h}$ at an enzyme \\ loading of $25 \mathrm{FPU} / \mathrm{g}$ cellulose. However, further lignin removal did not \\ increase the hydrolysis. The effect of enzyme loading on the \\ enzymatic hydrolysis was also explored in this work. It was concluded \\ that a high glucose yield of $90 \%$ was achieved when the enzyme \\ dosage was reduced from 25 to $15 \mathrm{FPU} / \mathrm{g}$ cellulose, which was \\ cost-effective for the sugar and ethanol production. The structures of \\ raw material and delignified samples were further characterized by \\ XRD and scanning electron microscopy (SEM).
}

Keywords: Furfural residues; Enzymatic hydrolysis; Lignin removal; Glucose yield

Contact information: Department of Chemical Engineering, Beijing Forestry University, Beijing 100083, China. *Corresponding author:jiangjx@bjfu.edu.cn

\section{INTRODUCTION}

Efficient conversion of lignocellulosic biomass to fermentable sugars is essential for the realization of economic bioethanol (Sheehan and Himmel 1999), and also has enormous potential in meeting global food and energy demand via biological route. Currently, enzymatic hydrolysis has attracted increasing attention as an alternative to acid hydrolysis for converting lignocellulosic materials to sugars. However, lignocellulosic biomass is naturally resistant to enzymatic attack because of the highly ordered structure of cellulose, limited binding sites available to enzymes, as well as the physical barrier provided by the hemicellulose and lignin surrounding cellulose (Cowling 1975). The enzymatic hydrolysis of cellulose can be enhanced by changing the physicochemical properties of the substrate such as crystallinity, degree of polymerization, surface area, and contents of lignin and hemicellulose (Puri 1984; McMillan 1994).

Furfural residues are the by-products of furfural industry, which are mainly obtained from corn cobs by acid catalysis at high temperature. They represent the sources having the highest potential for low-cost, high-volume production. It has been estimated that an average of 23 million tons of furfural residues were available annually for alternative use between 2006 and 2009 in China (Sun et al. 2008). However, furfural residues are considered as a waste and widely utilized for burning at present. The use of such waste residues for sugar and ethanol production would significantly reduce the cost of raw materials and be friendly to the environment. Furthermore, the furfural residues are almost free of hemicellulose, which is of benefit for the enzymatic hydrolysis. 
Although the effect of lignin on the enzymatic hydrolysis of pretreated biomass has been extensively studied, it is still a topic to debate in the literature. Lignin, a biologically resistant, netlike polymer surrounding cellulose and hemicellulose, correlates inversely with digestibility (Chang and Holtzapple 2000; Mansfield et al. 1999). Lignin is thought to impact cellulose conversion by either physically impeding cellulase access to cellulose, or reducing the effective concentration of cellulases by adsorbing the enzymes non-specifically (Eriksson et al. 2002; Mooney et al. 1998). In this study, the effect of lignin content on enzymatic hydrolysis of furfural residues was evaluated to obtain the high yield of sugar. The samples investigated here were treated with the sodium chlorite method to remove the lignin.

\section{EXPERIMENTAL}

\section{Materials}

The furfural residues were kindly supplied by the Chunlei Furfural Corporation (Hebei, China). The residues, which had a $\mathrm{pH}$ of 2 to 3 initially, were immersed in $1 \% \mathrm{NaOH}$ solution for half an hour and then washed with fresh distilled water until neutral. The samples were dried at $50{ }^{\circ} \mathrm{C}$ for $12 \mathrm{~h}$ and milled to give a size under 40 mesh. Corn cobs here were purchased in the supermarket and treated as the same way as furfural residues except for the alkali treatment. All of the materials were stored in sealed bags at room temperature until further processed.

\section{Methods}

\section{Lignin removal}

The furfural residues were delignified with sodium chlorite following a standard method (Ishizawa et al. 2009) at a liquid-to-biomass ratio of 80:1. The samples were suspended in water to form $3 \%(\mathrm{~g} / \mathrm{g})$ solids slurry, and then $0.5 \mathrm{~mL}$ of acetic acid and $1.5 \mathrm{~g}$ of sodium chlorite were added per equivalent gram of dry biomass. The mixture was heated to $70{ }^{\circ} \mathrm{C}$ with gentle swirling at intervals. Fresh amounts of acetic acid and sodium chlorite were added each hour until the samples were judged to be sufficiently delignified by the persistence of yellowish-green chlorine dioxide gas that was generated on mixing the reagents. Samples with different content of lignin were obtained after being treated for 1 to 5 hours, and they were labeled as $T_{1}, T_{2}, T_{3}, T_{4}$, and $T_{5}, T_{0}$ represents the raw material of neutralized furfural residue without delignification, taken as a comparison. All samples were thoroughly washed with distilled water until the wash was colorless and neutral, and then stored in a sealed bag at $4{ }^{\circ} \mathrm{C}$ before enzymatic hydrolysis.

\section{Enzymatic hydrolysis}

The enzyme used in this study was a commercial cellulase provided by Xiasheng Corporation (Ningxia, China), which has a filter-paper activity of $90 \mathrm{FPU} / \mathrm{g}$. Samples were enzymatically hydrolyzed at $50{ }^{\circ} \mathrm{C}$, pH 4.8 for $108 \mathrm{~h}$ in a $150 \mathrm{rpm}$ air shaker, with a cellulase loading of 5-25 FPU/g cellulose and substrate concentration of $2.5 \%(\mathrm{w} / \mathrm{v})$. Hydrolysates (about $2 \mathrm{ml}$ ) were taken at $6 \mathrm{~h}$ intervals for the first $36 \mathrm{~h}$ and $12 \mathrm{~h}$ intervals for the rest $72 \mathrm{~h}$, which were immediately centrifuged at $3500 \mathrm{rpm}$ for $10 \mathrm{~min}$ to prevent further hydrolysis. One-hour samples were taken to indicate the initial digestion rate. 


\section{Analytical methods}

Lignin content was determined as the summation of Klason lignin and acid-soluble lignin (Liu 2004; Ballesteros et al. 2004). The constituent of samples and the yield of glucose was determined and calculated by the National Renewable Energy Laboratory (NREL) methods (Sluiter et al. 2004). The sugar analysis was carried out by HPAEC (High Performance Anion-Exchange Chromatography, Dionex ICS3000, USA) with a pulsed amperometric detector (PAD) and an ion exchange Carbopac PA-20 column.

Biomass crystallinity was analyzed by wide-angle X-ray diffraction on an XRD-6000 instrument (Shimadzu, Japan) operated at $40 \mathrm{kV}$ and $200 \mathrm{~mA}$. Samples were scanned at $2 \% \mathrm{~min}$ from $2 \theta=5^{\circ}$ to $60^{\circ}$ with a step size of $0.2^{\circ}$. The crystallinity was determined as the percentage of crystalline material in the biomass and expressed as the crystallinity index $\left(\mathrm{Cr}_{\mathrm{I}}\right)$ (Wang et al. 2009),

$$
\mathrm{Cr}_{\mathrm{I}}=\left[\left(\mathrm{I}_{002}-\mathrm{I}_{\mathrm{am}}\right) / \mathrm{I}_{002}\right] \times 100
$$

in which $\mathrm{I}_{002}$ is the intensity for the crystalline portion of biomass at about $2 \theta=22.5^{\circ}$ and $\mathrm{I}_{\mathrm{am}}$ is the intensity for the amorphous portion at $2 \theta=18.7^{\circ}$.

The fracture surfaces of various samples were observed by scanning electron microscopy (SEM) (S-3400N, HITACHI, Japan) at acceleration voltages of $10 \mathrm{kV}$. Samples were coated with gold-palladium in a sputter coater (E-1010, HITACHI, Japan). The pictures were in the same magnification.

\section{RESULTS AND DISCUSSION}

\section{Chemical Composition of Substrates}

The compositions of raw material and delignified samples are presented in Table 1. It was shown that the xylan accounted for only a small portion of the furfural residue $(3.6 \%)$, which was significantly lower than that of corn cob $(41.3 \%)$. This implied that hemicellulose was mostly removed through the acid pretreatment for the furfural production. The lignin content was remarkably reduced from $45.1 \%$ to $1.3 \%$ with the increase of lignin removal, simultaneously increasing the cellulose amount in the remaining solids. Meanwhile, it was observed that the xylan disappeared during the sodium chlorite pretreatment, which was mainly due to the intimate association of hemicellulose with lignin, such that it was removed along with the lignin.

Table 1. Chemical Composition of Raw and Pretreated Materials

\begin{tabular}{|c|c|c|c|c|c|c|c|}
\hline Component (\%) & Corn cob & $\mathrm{T}_{0}{ }^{*}$ & $\mathrm{~T}_{1}$ & $\mathrm{~T}_{2}$ & $\mathrm{~T}_{3}$ & $\mathrm{~T}_{4}$ & $\mathrm{~T}_{5}$ \\
\hline Glucan & 28 & 43.9 & 50.6 & 59.7 & 70.3 & 87 & 98.1 \\
\hline Xylan & 41.3 & 3.6 & $\mathrm{ND}$ & $\mathrm{ND}$ & $\mathrm{ND}$ & $\mathrm{ND}$ & $\mathrm{ND}$ \\
\hline Lignin & 21.4 & 45.1 & 40.8 & 32.1 & 21.9 & 7.6 & 1.3 \\
\hline Lignin reduction & -- & 0 & 9.5 & 28.8 & 51.4 & 83.2 & 97.2 \\
\hline
\end{tabular}

Sun et al. (2011). "Lignin vs. enzyme hydrolysis," BioResources 6(1), 317-328. 


\section{Effect of Lignin Content on Enzymatic Hydrolysis}

There is a strong consensus that lignin removal plays an important role in enhancing biomass digestibility (Liao et al. 2005; Mooney et al. 1998). However, the extent of delignification required for high hydrolysis is still a subject of debate. The difference could depend on the biomass diversity, hydrolysis periods and cellulose loadings (Fan et al. 1981). In this study, several substrates with various lignin content were prepared and hydrolyzed, while the raw material and corn cob were hydrolyzed for comparison.

The initial rate in the release of glucose from enzymatic saccarification of various substrates is shown in Fig. 1. The initial rate was determined by the amounts of glucose release within $1 \mathrm{~h}$ at the beginning of enzymatic hydrolysis. As can be seen, delignification increased the initial hydrolysis rate, which is consistent with the results of Draude et al. (2001). The hydrolytic reaction initially occurs due to the cellulase attack on the cellulose surface. Since the initial rate of hydrolysis is dependent upon the number of available enzyme absorption sites on cellulose, delignification could only enhance the initial rate by increasing these sites through breaking the barriers between enzyme and cellulose. However, the initial rate of hydrolysis was slightly decreased when the lignin was completely removed, which was probable due to the generation of some inhibitors that affected the enzyme activity in the hydrolysis process.

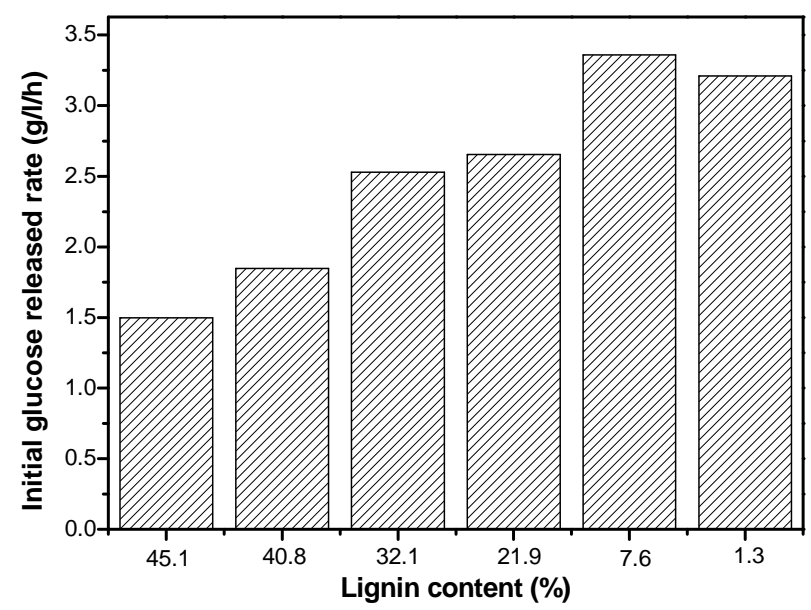

Fig. 1. Effect of lignin content on the initial rate of hydrolysis from furfural residues

The concentration and yield of glucose from the enzymatic hydrolysis of various substrates are presented in Fig. 2. The glucose released from the substrates was increased rapidly in the initial stage, and a glucose yield of $50 \%$ was achieved for most of samples during the first $12 \mathrm{~h}$, while the rate of hydrolysis progressively reduced as the reaction proceeded. This might be attributed to the gradual changes in ultrastucture, a decrease in enzyme activity by non-specific binding to lignin, and product inhibition (Ramos et al. 1993; Moriyama and Saida 1986). It has been suggested that the readily accessible regions are more efficiently hydrolyzed during the initial phase of hydrolysis, resulting in an accumulation of more recalcitrant cellulose that is harder to hydrolyze. 

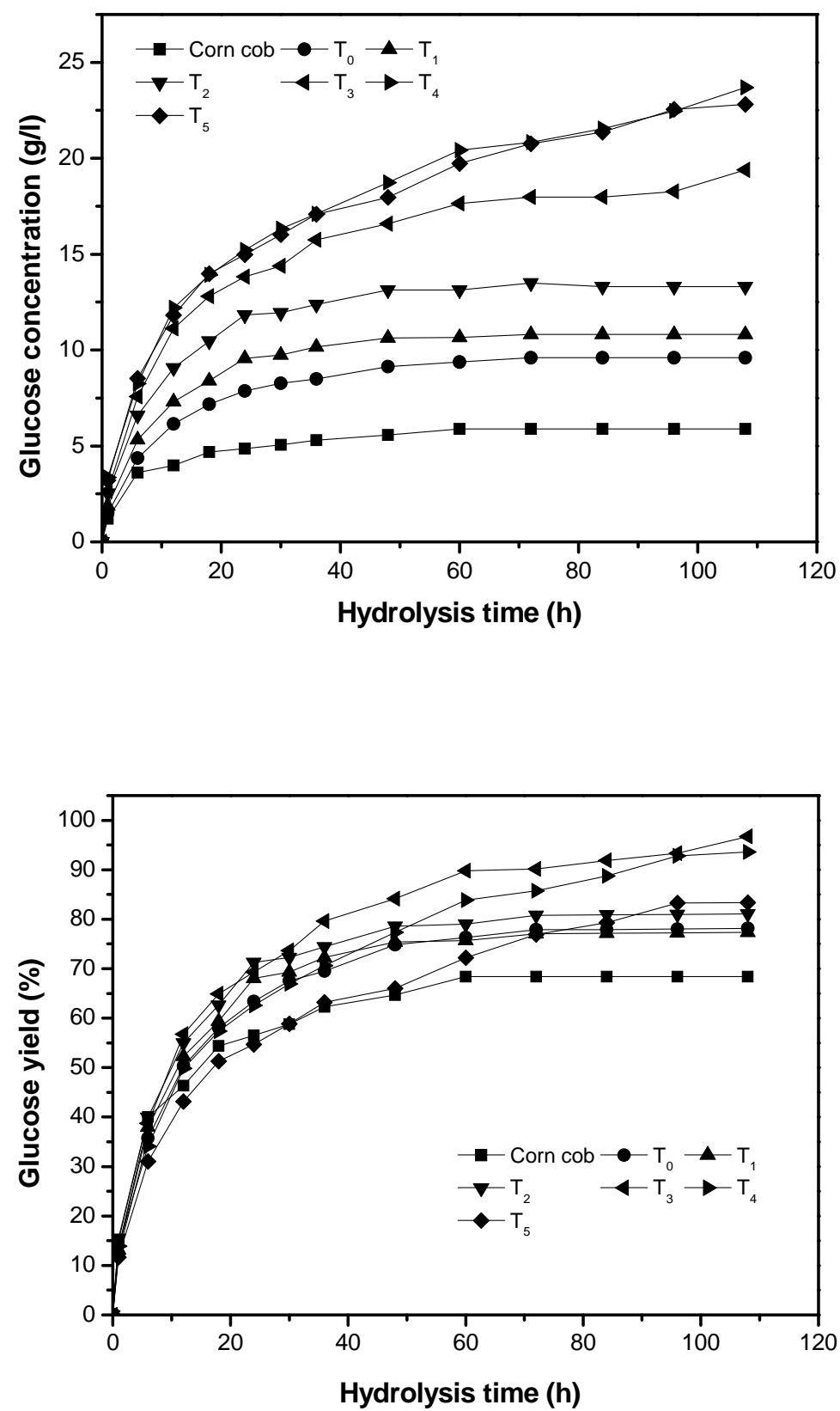

Fig. 2. Enzymatic hydrolysis of raw material and delignified samples.

* $T_{0}$ represents the raw material of neutralized furfural residue, while $T_{1}, T_{2}, T_{3}, T_{4}$, and $T_{5}$ represent furfural residue treated with sodium chlorite for $1,2,3,4$ and $5 \mathrm{~h}$, respectively.

The glucose concentration was raised remarkably from 5.8 to $23.7 \mathrm{~g} / \mathrm{L}$ by increasing the lignin removal. However, the glucose yield improved only slightly with further decrease of lignin content. The increase of yield became dramatic until $30 \%$ of the lignin had been removed. It was also found that the glucose yields from hydrolysis of samples with lignin removals over 50\% kept increasing after the first $48 \mathrm{~h}$, while 
that from the other samples started slowing down. This improvement in enzyme longevity could be due to the less binding of cellulase to the residual lignin. The maximum glucose yield of $96.8 \%$ was achieved when the sample with a lignin removal of $51.44 \%$ was hydrolyzed for $108 \mathrm{~h}$ at an enzyme loading of $25 \mathrm{FPU} / \mathrm{g}$ cellulose, which was $23.9 \%$ and $44.1 \%$ higher than those attained from furfural residue and corn cob, respectively. This strongly indicated that lignin was the most dominant resistance factor for the biomass hydrolysis. The results can be interpreted as follows: Delignification causes biomass swelling, disruption of lignin structure, and subsequently alleviates steric hindrance through increasing internal surface area and pore volume, thus reducing irreversible adsorption of enzyme on lignin and increasing enzyme accessibility to cellulose (Meunier and Penner 1999).

It was interesting to note that the yield of glucose was decreased when the removal of lignin exceeded 50\%. One plausible explanation for this phenomenon was that lignocellulose pores collapsed when the lignin was extensively removed, resulting in a reduction of available surface area for enzyme adsorption. In this work, the results probably were related to the method we used in removing the lignin, whereby the hydroxyl groups and reducing end groups of cellulose could be oxidized during the acidified sodium chlorite pretreatment (Fengel and Wegener 1984). Chemical oxidation of the reducing-ends of cellulose could negatively impact the interaction with the reducing-end and targeting cellobiohydrolase. Another interpretation of the results was that in the absence of hemicelluloses, lignin acts as a spacer among the cellulose microfibrils, and removing the lignin allows neighboring cellulose fibrils to aggregate into a less hydrolysable form (Ishizawa et al. 2009).

As Fig. 2 shows, the glucose yield of $78 \%$ obtained from the raw furfural residue was much higher than that of corn cob and most lignocellulosic materials reported (Ucar and Fengel 1988); this was attributed mainly to hemicellulose removal caused by the acid treatment, which increased the surface area and pore volume, making the cellulose more accessible to cellulase. On the other hand, it has been reported that lignin subjected to the high-temperature acid treatments can be chemically modified and recondensed as an altered lignin polymer, which might play a less detrimental role in digestibility (Gharpuray et al. 1983).

\section{The Effect of Enzyme Loading on the Required Hydrolysis Period}

The cost of cellulase accounts for at least $50 \%$ of the total cost in the cellulosic ethanol production, which is far more expensive than that of starch-hydrolyzing enzymes for corn kernel-based ethanol biorefineners. So it is important to determine the optimal enzyme loading used in the hydrolysis process, considering both the cost and sugar yield. Based on the above findings, $\mathrm{T}_{3}$ residue was chosen as the substance to study the effect of enzyme loading. It was hydrolyzed at the enzyme loadings of 5, $10,15,20$, and $25 \mathrm{FPU} / \mathrm{g}$ cellulose, respectively.

Figure 3 shows that the yield of glucose was improved by increasing the enzyme loading. The highest glucose yield of $96.8 \%$ was obtained at an enzyme loading of $25 \mathrm{FPU} / \mathrm{g}$ and reaction time of $108 \mathrm{~h}$. However, it was observed that the rate of increase of glucose yield declined as the enzyme loading increased. Only a minor increase on the yield of glucose $(6 \%)$ was noticed when the enzyme dosage increased from 15 to $25 \mathrm{FPU} / \mathrm{g}$ cellulose. It was concluded that $15 \mathrm{FPU} / \mathrm{g}$ cellulose was the optimal cellulase loading for the economical hydrolysis of furfural residues. 


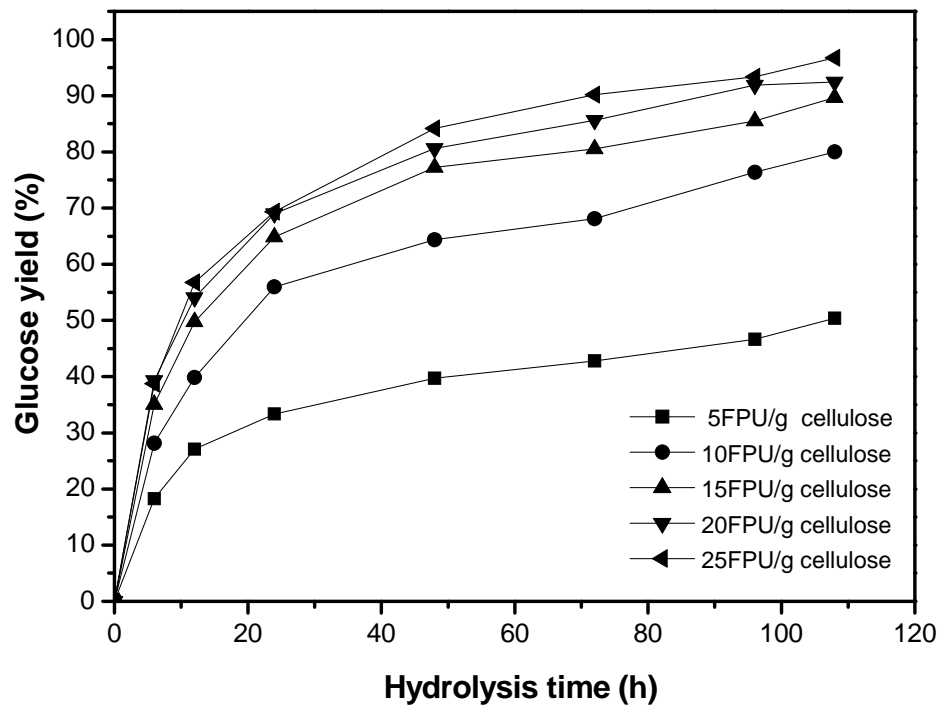

Fig. 3. Effect of cellulase loadings on the enzymatic hydrolysis of delignified sample $T_{3}$

\section{Crystallinity}

X-ray diffraction (XRD) has been extensively used to investigate the crystallinity of cellulose materials. Figure 4 shows the effect of lignin content on the crystallinity of samples before and after $108 \mathrm{~h}$ of enzymatic hydrolysis.

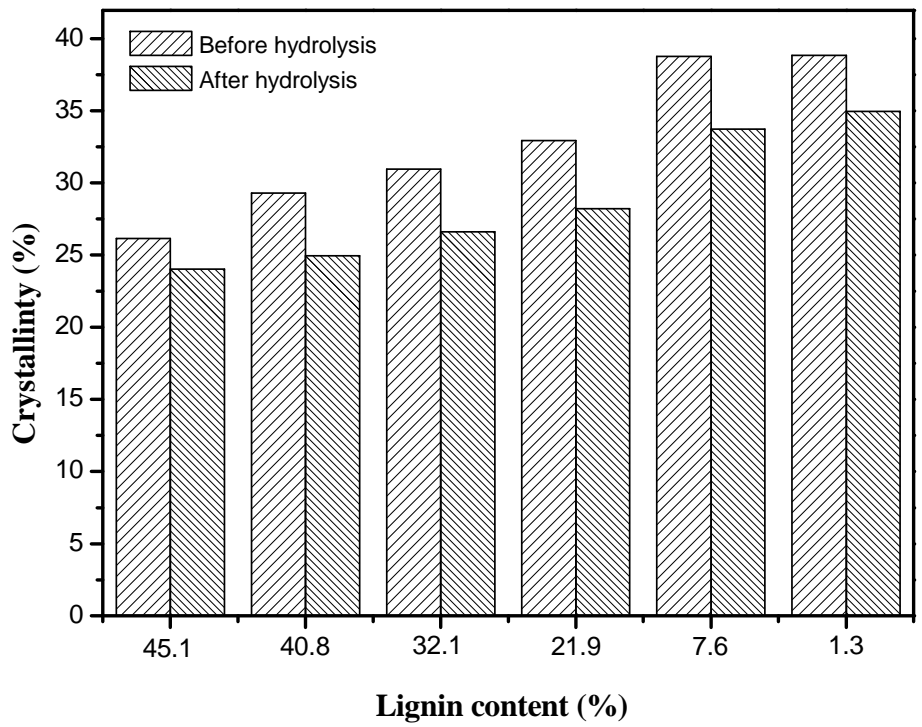

Fig. 4. Effect of lignin content on the crystallinity of samples before and after enzymatic hydrolysis for $108 \mathrm{~h}$ 
The results implied that the crystallinity of samples was generally increased as the amorphous material (i.e., lignin) was removed gradually, while a decrease in crystallinity could be observed for all hydrolyzed samples $(108 \mathrm{~h})$ because of the hydrolysis of crystalline cellulose in the substrates (Fig. 4). The wide-angle X-ray diffraction curves of different samples are shown in Fig. 5. The diffraction patterns are typical of the crystalline structures of cellulose I, with the main diffraction signals at $2 \theta$ values of $16.3^{\circ}$ and $22.5^{\circ}$, normally assigned to the diffraction planes 101 and 002 , respectively. It was shown that the peak of the diffraction plane 002 from the delignified samples was sharper than that of un-treated one, which was in agreement with the increased degree of crystallinity.

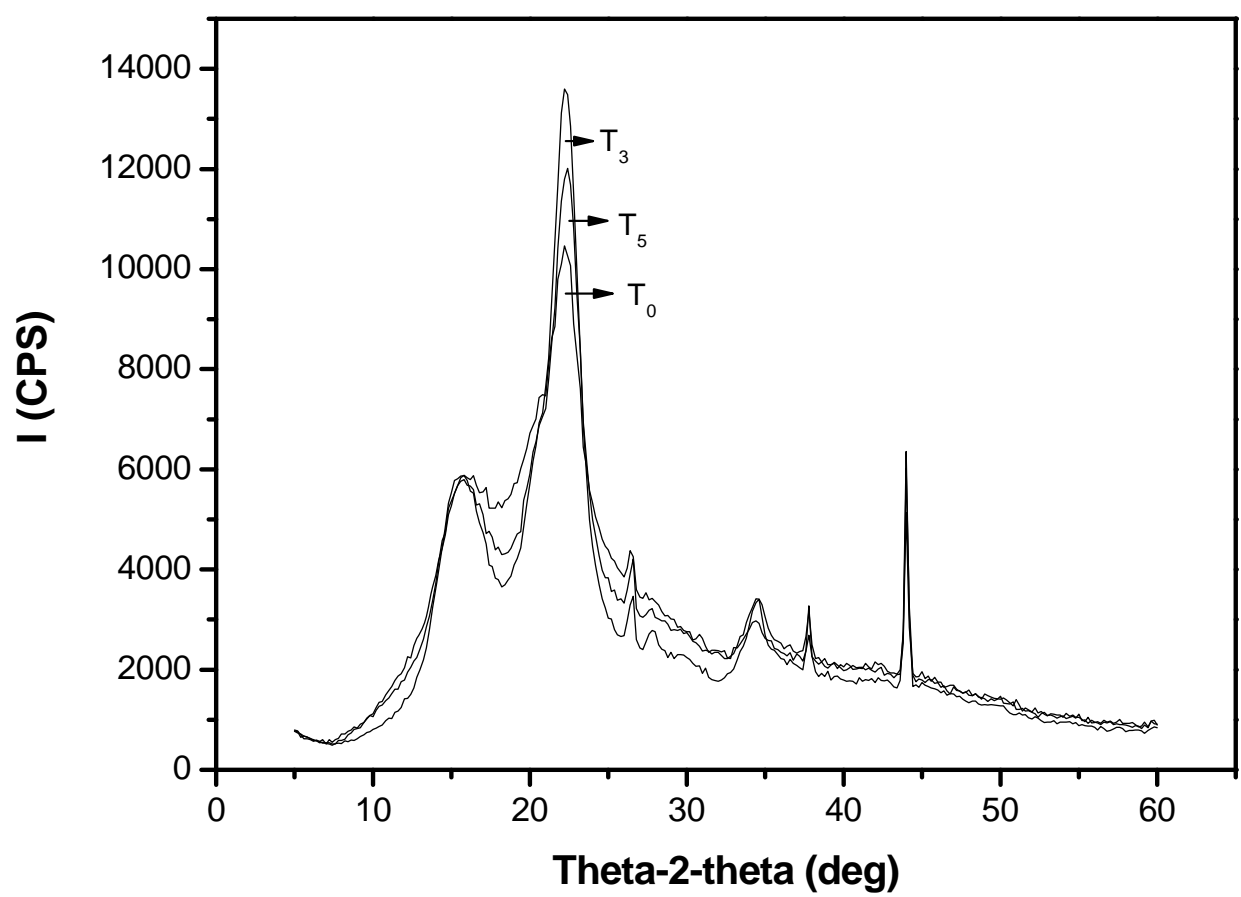

Fig. 5. X-ray diffraction patterns of raw material $T_{0}$ and delignified samples $T_{3}$ and $T_{5}$

The influence of hydrolysis time on the crystallinity of $\mathrm{T}_{3}$ residue is presented in Fig. 6. Crystalline cellulose is considered to be more difficult to degrade than the amorphous region due to the strong intermolecular hydrogen bonding between the cellulose chains. As a result, the cellulose $\mathrm{I}_{\alpha}$, para-crystalline, and non-crystalline regions were rapidly hydrolyzed during the initial phase of hydrolysis, bringing about an increase in the cellulose crystallinity (Weimer et al. 1995). After that, all cellulose polymorphs, including the more energetically stable cellulose $I_{\beta}$, were found to be equally susceptible to the enzymatic hydrolysis, so that thereafter the highly crystalline regions were gradually degraded, leading to the observed decrease of crystallinity. 


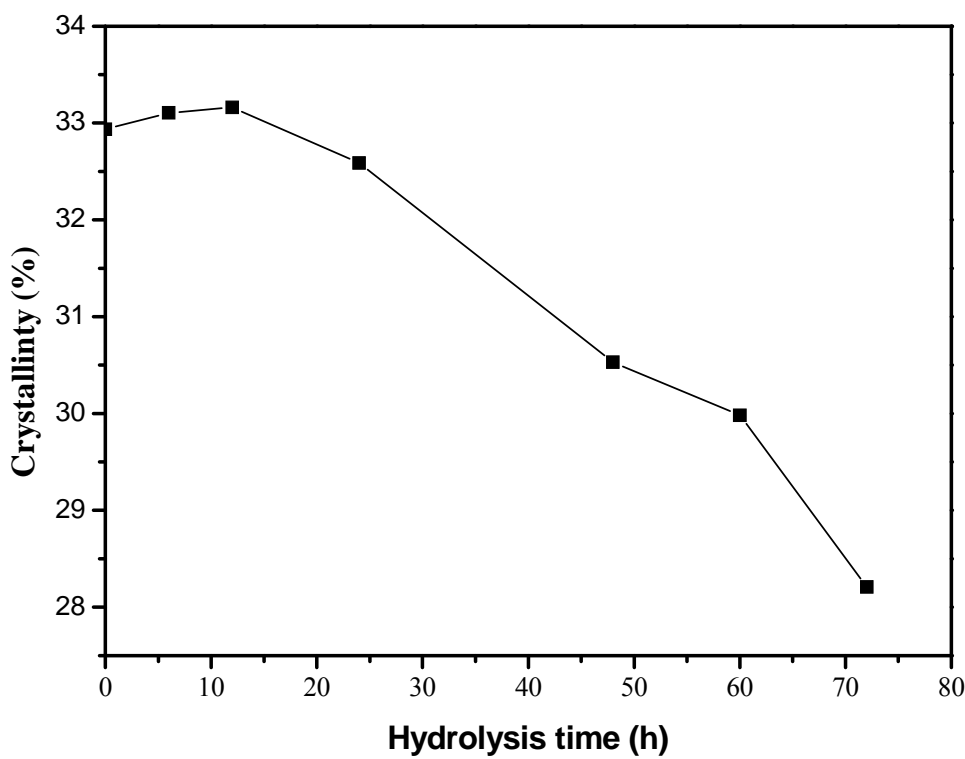

Fig. 6. Effect of hydrolysis time on the crystallinty of delignified sample $T_{3}$

\section{Morphological Structure}

The effectiveness of pretreatments in enhancing the hydrolysis rate may be due to the structural modification (Gharpuray et al. 1983). SEM micrographs of various samples were observed to verify the material structural changes caused by the pretreatments and hydrolysis (Fig. 7).

The surface of the raw material was uneven and covered with small droplets, which were ascribed to the melting of lignin at high temperature and subsequent condensation (Fig. 7A). The sample structures were strongly modified by dissolving the lignin fractions (Fig. 7A, C, E). The surface of the samples became smooth and most of the fibers were exposed, increasing the external surface area. It was obvious that some pores appeared when the lignin was removed, which was beneficial for the enzymatic attack on the cellulose, finally resulting in increased hydrolysis. A similar observation was reported by Ooshima et al. (1990). However, it was interesting to note that the fiber congregated into the form of a bundle when the lignin was completely removed (Fig. 7C), which is consistent with the previous hypothesis that the deep removal of lignin may have a negative factor on the enzymatic hydrolysis.

Figures $7 \mathrm{~B}, \mathrm{D}$, and $\mathrm{F}$ show the SEM pictures of hydrolyzed samples. It was noticeable that the fiber structure was destroyed after a hydrolysis process, and the break became more serious when the delignified degree increased, especially for the $\mathrm{T}_{3}$ residue in which the structure of fibers was complete destroyed, explaining the high glucose yield $(96.8 \%)$ obtained. 

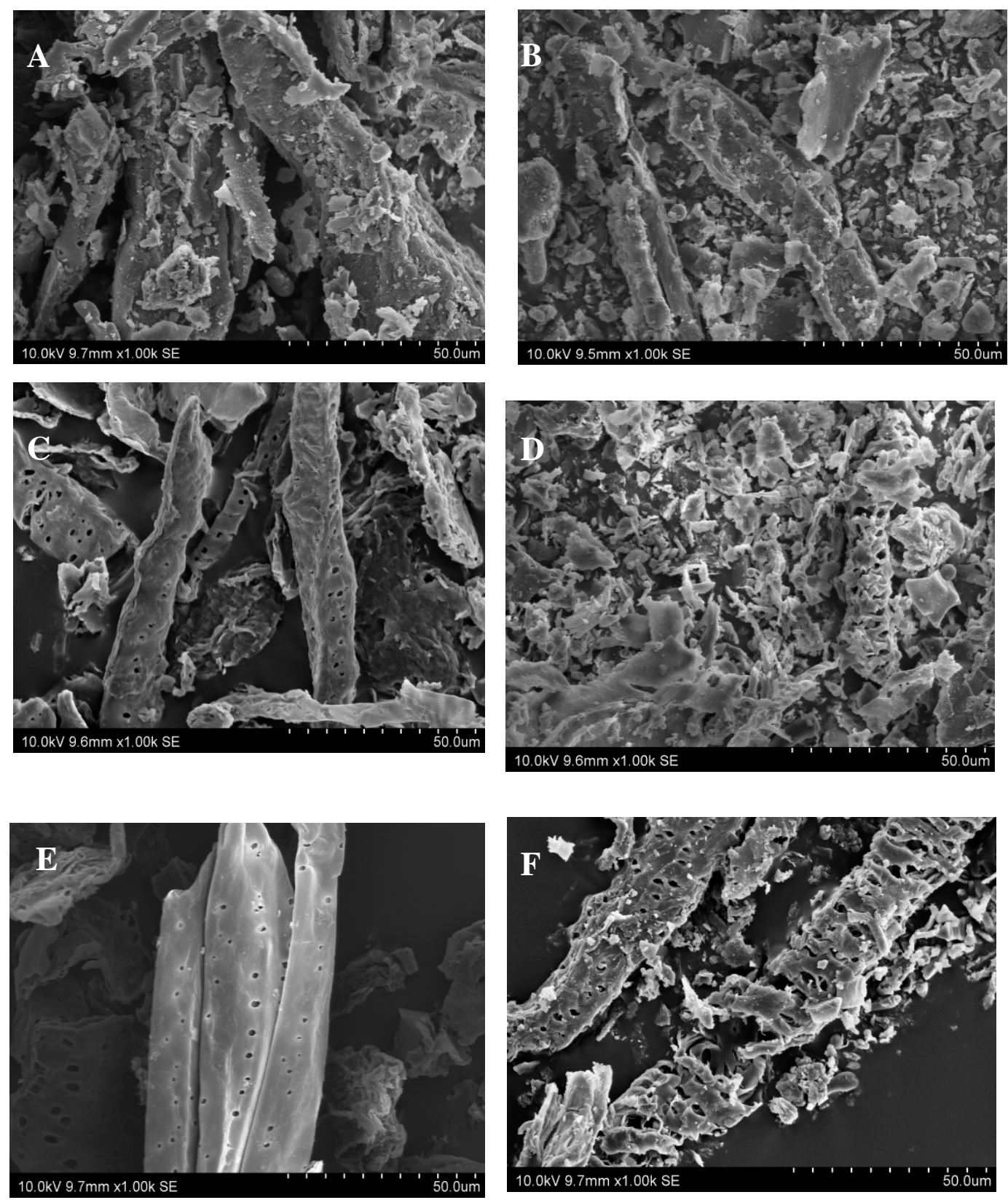

Fig. 7. Scanning electron micrographs of different samples: (A) raw material $T_{0}$; (B) raw matarial $T_{0}$ after $108 \mathrm{~h}$ enzymatic hydrolysis; $(C)$ delignified sample $T_{3}$; (D) delignified sample $\mathrm{T}_{3}$ after $108 \mathrm{~h}$ enzymatic hydrolysis; (E) delignified sample $\mathrm{T}_{5}$; $(\mathrm{F})$ delignified sample $\mathrm{T}_{5}$ after $108 \mathrm{~h}$ enzymatic hydrolysis

\section{CONCLUSIONS}

The effect of lignin content on enzymatic hydrolysis of furfural resides was studied in this work. The results showed that the hydrolysis was remarkably improved as the removal of lignin was increased up to $30 \%$. The maximum glucose yield of $96.8 \%$ was obtained when the sample with a lignin removal of $51.44 \%$ was 
hydrolyzed for $108 \mathrm{~h}$ at an enzyme loading of $25 \mathrm{FPU} / \mathrm{g}$ cellulose. However, the yield of glucose was decreased when the lignin was further removed. The SEM images indicated that lignin removal made the fiber fully exposed, increasing the surface area and the population of pores, which brought about an increase in glucose yield. It was also noticed that the fiber congregated into the form of a bundle when the lignin was completely removed, resulting a negative impact on the enzymatic hydrolysis. In addition, a high glucose yield of $90 \%$ was achieved when the low enzyme loading was used (15 FPU/g cellulose), which was cost-effective for the production of sugar and ethanol. In conclusion, furfural residues were found to have high potential for production of bioethanol from lignocellulosic sources, and the further work is in progress on finding an environment-friendly and mild pretreatment to remove the lignin for the commercial utilization of furfural residues.

\section{ACKNOWLEDGEMENTS}

The authors are grateful for the financial support of this research from National Science Foundation of China (31070510) and Major State Basic Research Projects of China (973-2010CB732204).

\section{REFERENCES CITED}

Ballesteros, S., Oliva, J. M., Negro, M. J., Manzanares, P., and Ballesteros, I. (2004). "Ethanol from lignocellulosic materials by a simultaneous saccharification and fermentation process (SFS) with Kluyveromyces marxianus CECT 10875," Process Biochem. 39, 1843-1848.

Chang, V. S., and Holtzapple, M. T. F. (2000). "Fundamental factors affecting biomass enzymatic reactivity," Appl. Biochem. Biotechnol. 84/86, 5-37.

Cowling, E. B. (1975). "Physical and chemical constraints in the hydrolysis of cellulose and lignocellulosic materials," Biotechnol. Bioeng. Symp. 5, 163-181.

Draude, K. M., Kurniawan, C. B., and Duff, S. T. B. (2001). "Effect of oxygen delignification on the rate and extent of enzymatic hydrolysis of lignocellulosic material," Bioresour. Technol. 79, 113-120.

Eriksson, T., Borjesson, J., and Tjerneld, F. (2002). "Mechanism of surfactant effect in enzymatic hydrolysis of lignocellulose," Enzyme Microb. Technol. 31, 353-364.

Fan, L. T., Lee, Y. H., and Beardmore, D. H. (1981). "The influence of major structural features of cellulose on rate of enzymatic hydrolysis," Biotechnol. Bioeng. 23, 419-424.

Fengel, D., and Wegener, G. (1984). Wood-Chemistry, Ultrastructure, Reactions, de Gruyter, New York and Berlin, Germany.

Gharpuray, M. M., Lee, Y. H., and Fan, L. T. (1983). "Structural modification of lignocellulosics by pretreatments to enhance enzymatic hydrolysis," Biotechnol. Bioeng. 25, 157-172.

Ishizawa, C. I., Jeoh, T., Adney, W. S., Himmel, M. E., Johnson, D. K., and Davis, M. F. (2009). "Can delignification decrease cellulose digestibility in acid pretreated corn stover," Cellulose 16(4), 677-686.

Liao, W., Wen, Z., Hurley, S., Liu, Y., Liu, C., and Chen, S. (2005). "Effects of hemicellulose and lignin on enzymatic hydrolysis of cellulose from dairy 
manure," Applied Biochemistry and Biotechnology 121/124, 1017-1030.

Liu, S. C. (2004). Analysis and Measurement in Papermaking Industry, Chemical Industry Press, Beijing.

Mansfield, S. D., Mooney, C., and Saddler, J. N. (1999). "Substrate and enzyme characteristics that limit cellulose hydrolysis," Biotechnol. Prog. 15, 804-816.

Mcmillan, J. D. (1994). "Pretreatment of lignocellulosic biomass," In: Himmel, M. E., Baker, J. O., and Overend, R. P. (eds.), Conversion of Hemicellulose Hydrolyzates to Ethanol, American Chemical Society Symposium, Washington, 292-324.

Meunier, L., and Penner, M. H. (1999). "Enzyme-catalyzed saccharification of model celluloses in the presence of lignacious residues," J. Agric. Food Chem. 47, 346-351.

Mooney, C. A., Mansfield, S. D., Touhy, M. G., and Saddler, J. N. (1998). "The effect of initial pore volume and lignin content on the enzymatic hydrolysis of softwoods," Bioresour. Technol. 64, 113-119.

Moriyama, S., and Saida, T. (1986). "Continuous pretreatment and enzymatic saccharification of lignocellulosics," In: Young, R. A., and Rowell, R. M. (eds.), Cellulose: Structure, Modification and Hydrolysis, Wiley Interscience, New York, 323-335.

Ooshima, H., Burns, D. S., and Converse, A. O. (1990). "Adsorption of cellulase from Trichoderma reesei on cellulose and lignacious residue in wood pretreated by dilute sulfuric acid with explosive decompression," Biotechnol. Bioeng. 36, 446-452.

Puri, V. P. (1984). "Effect of crystallinity and degree of polymerization of cellulose on enzymatic saccharification," Biotechnol. Bioeng. 26, 1219-1222.

Ramos, L. P., Nazhad, M. M., and Saddler, J. N. (1993). "Effect of enzymatic hydrolysis on the morphology and fine structure of pretreated cellulosic residues," Enzyme Microb. Technol. 15, 821-831.

Sheehan, J., and Himmel, M. E. (1999). "Enzymes, energy, and the environment: Cellulase development in the emerging bioethanol industry," Biotechnol. Prog. 15, 817-827.

Sluiter, A., Hames, B., Ruiz, R., Scarlata, C., Sluiter, J., and Templeton, D. (2004). Laboratory Analytical Procedure, NREL Biomass Program.

Sun, Y. D., Sun, R., Jiang, J. X., and Zhu, L. W. (2008). "Process of conversion of the residue of furfural manufacture to ethanol by simultaneous saccharification and fermentation," Mod. Chem. Ind. 28(12), 48-52.

Ucar, G., and Fengel, D. (1988). "Characterization of the acid pretreatment for the enzymatic hydrolysis of wood," Holzforschung 42, 141-148.

Wang, K., Jiang, J.X., Xu, F., and Sun, R.C. (2009). "Influence of steaming pressure on steam explosion pretreatment of Lespedeza stalks (Lespedeza crytobotrya): Part 1. Characteristics of degraded cellulose," Polym. Degrad. Stabil. 94, 1379-1388.

Weimer, P. J., Hackney, J. M., and French, A. D. (1995). "Effects of chemical treatments and heating on the crystallinity of celluloses and their implications for evaluating the effect of crystallinity on cellulose biodegradation," Biotechnol. Bioeng. 48(2), 169-178.

Article submitted: September 25, 2010; Peer review completed: November 30, 2010; Revised version received and accepted: December 6, 2010; Published: Dec. 7, 2010. 